\title{
Infection and the People' s Rights Regarding MERS in the Republic of Korea
}

\section{Mi Jeong Park}

Seoul National University College of Medicine, Seoul, Republic of Korea

*Corresponding author: Park MJ, Senior Researcher, Seoul National University College of Medicine, Seoul, Republic of Korea, Tel: 821090064581; E-mail: apotre@snu.ac.kr;13apotre@gmail.com

Received date: February 20, 2018; Accepted date: March 10, 2018; Published date: March 17, 2018

Copyright: @ 2018 Park MJ. This is an open-access article distributed under the terms of the Creative Commons Attribution License; which permits unrestricted use; distribution; and reproduction in any medium; provided the original author and source are credited.

\begin{abstract}
The first case was reported on May 20, 2015. The outbreak was traced back to a Korean man who returned from a trip to Bahrain via Qatar in early May and sought medical care at several hospitals before being diagnosed. But this patient did not initially report his travel to the Middle East, which significantly delayed the process identifying the source of the epidemic.

In Korea, a total of 26 first generation cases in a single hospital were traced back to a single index case (patient zero). In particular, \#14 confirmed case occurred outbreak of SAMSUNG Medical Center, infected at least 90 cases. SAMSUNG Medical Center is one of the five largest hospitals located in Seoul with 3,980 healthcare professionals and more than 8,000 outpatient visits per day.

As a matter of fact, most of the people infected with MERS or who faced the risk of becoming infected with the disease appear to be those who stayed at the hospitals where patients of the disease were being housed. However, when the spread of the disease reached its peak in early June, a thousand or more schools and kindergartens were temporarily shut down, and a number of public events and festivals were cancelled. It was reported that the number of tourists visiting Korea decreased by $41 \%$ compared with the same time period of the previous year. During this time period, 16,752 people were ordered to stay in isolation within their own homes.
\end{abstract}

Keywords: MERS; Human rights; Infectious disease law; Isolation; Quarantine

\section{Introduction}

\section{Infectious diseases law and its limitations}

At that time, In Korea, "Infectious Diseases Control and Prevention Act" is to contribute the improvement and maintenance of citizens' health by preventing the occurrence and prevalence of infectious diseases hazardous to citizens' health, and prescribing necessary matters for the prevention and control thereof. But the law has some critical drawbacks in dealing with emerging infectious diseases as following.

\section{Limited Coverage}

What we should be especially concerned about in introduce a special act that deals with all matters relevant to emerging infectious diseases?

During the MERS outbreak, Korean public health authorities enforced many public health measures that were not authorized in the law. It is because the scope of the current law was too limited to cover MERS. For example, all residents of a farming town were ordered to stay home and leave their work for more than two weeks, but the order was not based on the law and some criticized it as arbitrary. So, we think it is necessary to include in the law what type of public health measures are enforceable (e.g., quarantine, isolation) under what conditions and what processes should be followed to protect the human rights of possible MERS patients [1,2]. The law limits its objectives to regulating "the infectious diseases that are specified by the Minister of the Ministry of Health and Welfare." In other words, this law covers only the diseases that are designated by the administrative regulation. As a result, the law does not provide legitimacy for government with regards to new (emerging) health-related risk factors or biological terrors that are not listed in the regulation, including MERS.

\section{Lack of Legal Grounds for Public Health Measures}

How should we design public health measures and procedures to protect the human rights of possible MERS patients?

Lack of legal provisions made public health authorities hesitant to take any public health measures that involve human rights restrictions because they have no legal basis to justify their decision. Public health authorities also felt no responsibility to take any action because they were not mandated to do so under the law. Many point to the lack of legal ground as the reason of the delayed actions of public health authorities. On the other hand, lack of legal provision also made the public distrustful about public health authorities.

When thinking about these policy questions, we find it very difficult to find a balancing point where the human rights of possible MERS patients and the rights of the public are equally protected. In general, 
public health measures are unconstitutional if they excessively restrict the rights of an individual. But, in the case of emerging infectious diseases, it is often difficult to decide (at the time when public health measures are being taken) whether the measure is excessively restrictive. Little is known about the disease at the time of the outbreak, so there is little information to help make an informed decision about whether the measure is too restrictive of human rights and if there is another measure that is less intrusive but is equally effective [3-6].

\section{Lack of Collaborative Structure within Government}

\section{What should we make a structure for these three levels of government and the roles that each level should assume?}

One of the problems in the response against MERS was a lack of collaboration among autonomous districts. Even after the central government announced the state of emergency, each health center adhered to the directions of its district and they did not attempt to collaborate with other districts. Korea has three levels of government: the central government, special self-governing provinces, and $\mathrm{Si} / \mathrm{Gun} / \mathrm{Gu}$, but the infectious disease law does not distinguish among the roles of each level of government and does not state how these governments should be vertically integrated in a state of emergency $[6,7]$. Autonomous district heads are elected through a democratic process, so they have independent legitimacy in running their government, including public health centers.

\section{Discussion and Conclusion}

Infectious diseases law is to establish a specific national public health and security measurement system to prevent and manage infectious diseases that may threaten society and/or cause damage and loss to the nation, such as new and mutant infectious diseases, diseases resulting from biological terrors, antibiotic resistant bacteria, zoonosis, vaccinated infectious diseases that can be exterminated, etc., and to safeguard the human rights of the infected persons.

The key point of a response system for infectious diseases is to offer an appropriate balance in case conflicts arise between having to efficiently cut off the spread of an infectious disease, and safeguarding the human rights of patients and those who are suspected of carrying or being at risk for the disease. In such situations, it is often unavoidable to restrict the freedom and rights of citizens while imposing a legal onus. People who are infected with an infectious disease due to lack of control or by way of reasons other than personal intentions or negligence, or any damage to a quarantine or isolation order shall be indemnified by the nation.

Liabilities of the nation and civil servants; public organizations, emergency health workers and civil servants shall diligently carry out their tasks to address the public health crisis, pursuant to the Act. People who are infected with an infectious disease due to lack of control or by way of reasons other than personal intentions or negligence, or any damage to a quarantine or isolation order shall be indemnified by the nation.

The administrative jurisdiction during a public health crisis, rules to encourage/obligate collaboration among different districts. For such structural reform, we think a manual should be produced to set up the detailed collaboration process among governments, and regular training should be conducted based on that manual.

\section{References}

1. Buchanan DR (2008) Autonomy, paternalism, and justice: ethical priorities in public health. Am J Public Health 98: 15.

2. Gostin LO (2005) World Health Law: Toward a new conception of global health governance for the 21st century. Yale J Health Pol'y L \& Ethics 5: 413-424.

3. Gian FG, Yacoub MH, Conti AA (2004) The concept of quarantine in history: from plague to SARS. J Infect 49: 257-261.

4. Oboho IK, Tomczyk SM, Al-Asmari AM, Banjar AA, Al-Mugti H, et al. (2015) 2014 MERS-CoV outbreak in Jeddah: A link to health care facilities. N Engl J Med 372: 846-854.

5. http://adilet.zan.kz/eng/docs/O8500000001

6. http://apps.who.int/iris/handle/10665/251717

7. https://www.gpo.gov/fdsys/granule/USCODE-2010-title42/ USCODE-2010-title42-chap6A-subchapII-partG-sec264 